\title{
JEWELLED CADDIS-WORM CASES
}

\section{By Charles T. Brues}

During the summer of 1930 while collecting in the northwestern part of Nevada, I secured some caddis-worm cases which have interested me greatly on account of a striking peculiarity evinced by these larval Trichoptera in selecting the minute stones that serve as material for covering their cases.

We were returning from a sojourn in the far northwestern, almost uninhabited, desert portion of the state, where permanent water is to be found at very few places. Reaching Fish Springs at dusk we decided to camp for the night close to the spring which furnishes sufficient cold water to form a tiny stream and a series of several small pools before it is absorbed and disappears in the soil. Examining the spring and short stream the next morning, I noticed in the blackish mud that numerous minute glistening bits of opal flecked the dark background. It is not surprising to find opal at this place, as there are extensive deposits of opal and opalized wood in the contiguous country to the northeast, where the material is mined commercially. All the pieces in the spring were small or minute, but they emitted a brilliant pale blue fire.

We collected a number of aquatic insects and noticed a concerted movement of the fiery opal flecks upon the bottom, which proved to be a caddis-fly dragging its case across the surface of the mud. Search revealed a number of others and finally we obtained nine specimens, each thickly jewelled with bits of opal. As the amount of opal in the muddy bottom of the spring was far less in proportion to the other sandy or crystalline material than it is in the assortment utilized by the caddis-fly larvæ, there can be no doubt that the brilliant color of the opal in some way influences the larvæ in their choice. The cases are covered with sand, 
and under the microscope the particles are seen to be in part crystalline (consisting of broken bits of highly refractive quartz) and in part dull opaque, usually yellow, brown or dark colored, non-crystalline material. The transparent particles are all opalized to some extent, although some are much more brilliant or "fiery" than others. A count of the particles from two cases, after removing them from the silken network by immersion in a caustic potash solution, shows that more than half are opalized to some extent. Thus in one case the ratio of crystalline and opalized particles to dull ones is 102:68 and in another $380: 222$. On the other hand, the amount of material from which selection is made by the larvæ shows a far smaller, though difficult to estimate, proportion of opal.

Several caddis-worms are known to exhibit a considerable intra-specific variation in selecting the material for their cases, depending usually upon what material is within reach. Lloyd ('21) describes a clear-cut example of this in Limnephilus combinatus, where he found either shells or bits of bark used by the larvæ in accordance with the availability of the two types of material. Here and in other species, e. g., in Phryganea vestita and Limnephilus submonilifer, such differences are to some extent associated with age, as the younger and older larvæ build cases of a different structure, or again the larvæ may migrate as they mature and leave the area where certain materials are available. Some species are furthermore quite indiscriminate in their choice of building material.

It would seem that the sense of discrimination of caddisworms in general in selecting objects to attach to their cases is such that it may be entirely dependent upon a tactile sense coupled with an appreciation of weight. Even where crystalline sand is chosen and rounded grains discarded, the same is true. Thus, the almost exclusive use of small quartz crystals by some species need not involve vision, as the latter may be recognized by their sharp edges.

In the present case vision must, however, form a necessary factor in the selection, as the brilliant opalized bits are not physically different from the white or slightly opalized pieces of quartz. All undoubtedly are of the same 
origin, having been formed as crystallization products in connection with fossilized wood that was silicified in extinct hot springs.

As a brief examination of the voluminous literature on caddis-worms has yielded no definite statements relative to the part played by vision in the choice of case-building material, it has seemed appropriate to present the accompanying observations.

I have not been able to determine the larva accurately, but it is structurally very similar to that of Platyphylax designatus, and undoubtedly belongs to some rather closely related form. Professor Banks has suggested that it may quite likely belong to one of two species of Heterophylax that are common in that part of the United States, $H$. magnus Banks or $H$. occidentalis Banks. On account of their size it is probable that they may be the latter species, as this is decidedly the smaller form. 

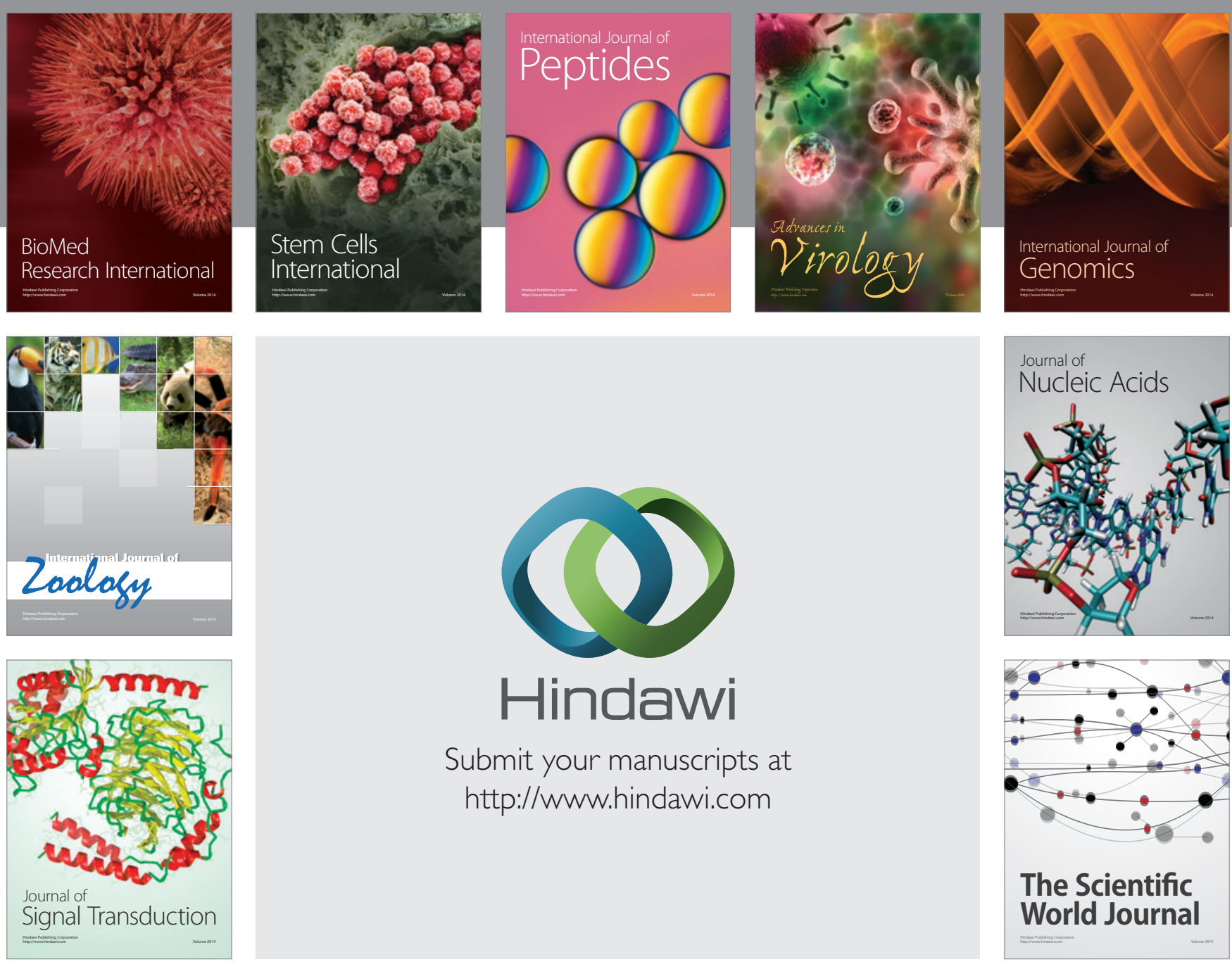

Submit your manuscripts at

http://www.hindawi.com
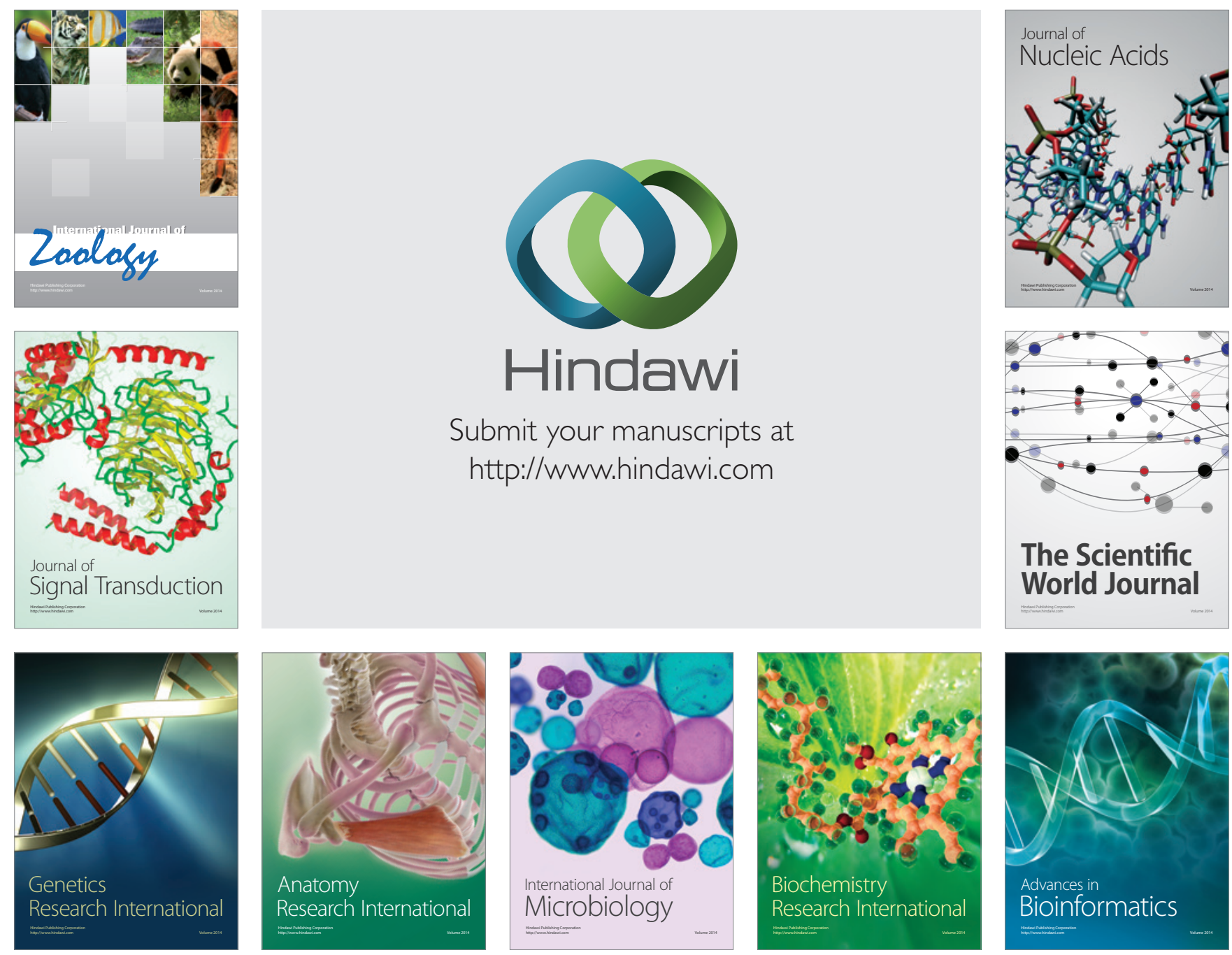

The Scientific World Journal
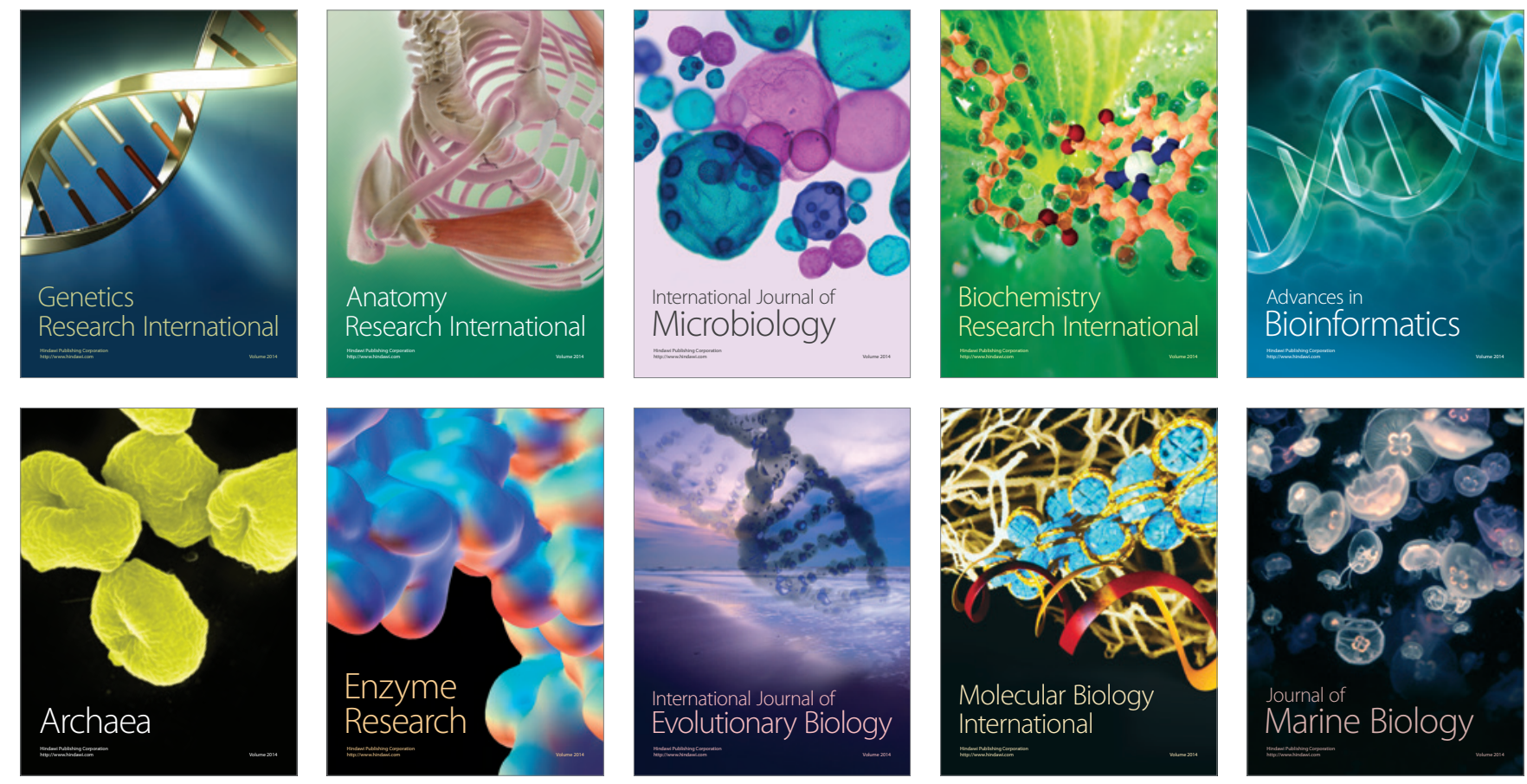